$12-1-2021$

\title{
Predicting risk factors for thromboembolic complications in patients with sickle cell anaemia - lessons learned for prophylaxis
}

\author{
Salam Alkindi \\ Sultan Qaboos University Hospital \\ Anwaar R Al-Ghadani \\ Sultan Qaboos University Hospital \\ Samah R Al-Zeheimi \\ Sultan Qaboos University Hospital \\ Said Y Alkindi \\ Al-Nahdha Hospital

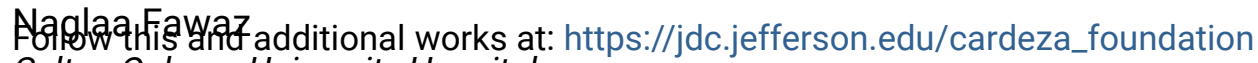 \\ Sylltan Qaboos University Hospital \\ Part of the Hematology Commons \\ Let us know how access to this document benefits you
}

\section{Recommended Citation}

Alkindi, Salam; Al-Ghadani, Anwaar R; Al-Zeheimi, Samah R; Alkindi, Said Y; Fawaz, Naglaa;

Ballas, Samir K.; and Pathare, Anil V, "Predicting risk factors for thromboembolic complications in patients with sickle cell anaemia - lessons learned for prophylaxis" (2021). Cardeza

Foundation for Hematologic Research. Paper 69.

https://jdc.jefferson.edu/cardeza_foundation/69

This Article is brought to you for free and open access by the Jefferson Digital Commons. The Jefferson Digital Commons is a service of Thomas Jefferson University's Center for Teaching and Learning (CTL). The Commons is a showcase for Jefferson books and journals, peer-reviewed scholarly publications, unique historical collections from the University archives, and teaching tools. The Jefferson Digital Commons allows researchers and interested readers anywhere in the world to learn about and keep up to date with Jefferson scholarship. This article has been accepted for inclusion in Cardeza Foundation for Hematologic Research by an authorized administrator of the Jefferson Digital Commons. For more information, please contact: JeffersonDigitalCommons@jefferson.edu. 


\section{Authors}

Salam Alkindi, Anwaar R Al-Ghadani, Samah R Al-Zeheimi, Said Y Alkindi, Naglaa Fawaz, Samir K. Ballas, and Anil V Pathare 


\title{
Predicting risk factors for thromboembolic complications in patients with sickle cell anaemia - lessons learned for prophylaxis
}

Journal of International Medical Research 49(II) I-II

(C) The Author(s) 2021 Article reuse guidelines: sagepub.com/journals-permissions DOI: I0.I I77/030006052। I 055385 journals.sagepub.com/home/imr @SAGE

\author{
Salam Alkindi' ${ }^{1,2}$, Anwaar R Al-Ghadani', \\ Samah R Al-Zeheimi', Said Y Alkindi ${ }^{3}$, \\ Naglaa Fawaz ${ }^{1,2}$, Samir K Ballas ${ }^{4}$ and \\ Anil V Pathare'
}

\begin{abstract}
Objective: To assess the clinical and laboratory predictors of venous thromboembolism (VTE) in patients with sickle cell anaemia (SCA) and its relationship to morbidity and mortality.

Methods: This retrospective case-control study analysed data from patients with SCA that experienced VTE compared with matched control patients with SCA but no VTE (2:I ratio).

Results: A total of 102 patients with SCA were enrolled (68 cases with VTE and 34 controls). Amongst the 68 cases (median age, 29.5 years), 26 (38.2\%) presented with isolated pulmonary embolism (PE). A higher prevalence of splenectomy (73.5\% versus $35.3 \%$ ) was observed in the cases compared with the controls. A significantly higher prevalence of central venous catheter (CVC) insertion ( $42.6 \%$ versus $8.8 \%$ ) was observed in the cases compared with the controls. High white blood cell counts, serum lactic dehydrogenase (LDH), bilirubin and C-reactive protein (CRP) and low haemoglobin $(\mathrm{Hb})$ and $\mathrm{HbF}$ were significant risk factors for VTE. Forty-two cases (6I.8\%) developed acute chest syndrome, 10 (14.7\%) had a stroke and seven (10.3\%) died. Conclusions: VTE in patients with SCA has a high impact on morbidity and mortality. PE was the leading presentation of VTE, with CVC insertion, high LDH, bilirubin, CRP and white blood cell counts along with low $\mathrm{Hb}$ and $\mathrm{HbF}$ constituting other significant risk factors.
\end{abstract}

\footnotetext{
'Department of Haematology, Sultan Qaboos University Hospital, Muscat, Oman

${ }^{2}$ College of Medicine \& Health Sciences, Muscat, Oman

${ }^{3}$ Department of Internal Medicine, Al-Nahdha Hospital, Muscat, Oman
}

\footnotetext{
${ }^{4}$ Cardeza Foundation for Hematologic Research, Thomas Jefferson University, Philadelphia, PA, USA

Corresponding author:

Salam Alkindi, Department of Haematology, College of Medicine \& Health Sciences, Sultan Qaboos University, P. O. Box 35, Muscat 123, Sultanate of Oman. Email: sskindi@yahoo.com
} 


\section{Keywords}

Venous thromboembolism, sickle cell disease, pulmonary embolism

Date received: 19 June 202I; accepted: 6 October 2021

\section{Introduction}

Sickle cell anaemia (SCA) is a common and life-threatening haematological disorder that affects millions of people worldwide. ${ }^{1,2}$ In Oman, SCA is a major public concern, where $5.7 \%$ of the population carry the sickle cell gene and $0.3 \%$ Omani people have SCA. ${ }^{3,4}$ It is a monogenic recessively inherited disorder with abnormal betaglobin alleles, where glutamic acid is replaced by valine in the haemoglobin subunit beta $(H B B)$ gene. ${ }^{5,6}$ Upon deoxygenation, this genetic mutation causes erythrocytes to undergo intracellular polymerization in which flexible biconcave shaped red cells change into an elongated rigid form (sickled cells). As the process of sickling and unsickling continues, the erythrocyte membrane loses the flexibility to change and the cell remains permanently sickled. ${ }^{7}$ Sickled red blood cells are rigid with a non-deformable membrane and are prematurely destroyed leading to a chronic haemolytic anaemia., The intravascular haemolysis of red blood cells results in elevated free plasma haemoglobin with depletion of nitric oxide in the microcirculation contributing to the high prevalence of morbidity and mortality in adults with SCA. ${ }^{8}$

Sickled erythrocytes occlude blood vessels and disrupt blood flow, causing repeated ischaemia and inflammation. This vessel occlusion is a complex process involving an interaction between the sickle cell, vessel endothelial cells, platelets and other blood components. ${ }^{9,10}$ The adherence of the sickle cell to the vessel endothelium results in activation of the endothelial cells and secretion of inflammatory mediators and biomarkers that increase platelet activation and induce blood coagulation. ${ }^{10}$

Patients with SCA frequently develop acute pulmonary complications, including acute chest syndrome (ACS), asthma and a higher risk for thromboembolism. ${ }^{1-13}$ Several mechanisms have been suggested to explain this hypercoagulability including platelet reactivity, with elevated plasma concentrations of platelet-derived microparticles, hydroxyl radical formation, fibronectin and thrombospondin elevation, deficient proteins $\mathrm{S}$ and $\mathrm{C}$, and elevated levels of factor VIII and tissue factor. ${ }^{14,15}$

Several studies in SCA patients have recorded a high prevalence of venous thromboembolism (VTE). ${ }^{16-18}$ These studies found that the incidence of VTE events in SCA patients was higher than in the nonSCA population. ${ }^{16-18}$ Also, several laboratory parameters were abnormal in the patients with VTE such as heterozygosity for factor $\mathrm{V}$ Leiden, elevated platelet counts as well as high factor VIII: C levels. ${ }^{18}$ A previous study that investigated the prevalence of pulmonary embolism (PE) and deep vein thrombosis (DVT) in SCA patients reported that $0.44 \%$ of patients had a discharge diagnosis of PE and DVT, as compared with $0.12 \%$ of nonSCA patients, indicating a significantly high prevalence. $^{18}$ A previous study reported that the cumulative incidence of VTE was $17.1 \%$ for severe sickle cell disease (SCD) patients (hospitalized $\geq 3$ times a year) versus $8.0 \%$ for the matched asthma controls and was associated with increased 
mortality. ${ }^{19}$ The Cooperative Study of Sickle Cell Disease on 1523 SCD patients aged $\geq 15$ years with 8862 years of followup reported an incidence rate for first VTE of 5.2 events $/ 1000$ person-years $(95 \%$ confidence interval [CI] 3.8, 6.9) with a cumulative incidence of $11.3 \%(95 \%$ CI $8.3,15.3)$ by age 40 years. $^{20}$ Thus, it is apparent that SCA is a risk factor for DVT and PE.

This current study aimed to assess the clinical and pathological characteristics of VTE amongst patients with SCA in order to determine the predisposing factors and determine its impact on morbidity and mortality.

\section{Patients and methods}

\section{Patient population}

This retrospective case-control study enrolled consecutive patients presenting with thromboembolic complications including unprovoked PE, upper and lower extremity DVT, portal vein thrombosis (PVT), superior vena cava thrombosis, right atrial thrombosis and cerebrovascular accident (CVA) in the Department of Haematology, Sultan Qaboos University Hospital, Muscat, Oman between January 2007 and January 2018. The inclusion criterion for the case group was patients with SCA that were admitted with venous thrombosis or thromboembolic complications. Patients that had SCA without thrombosis that attended the outpatient clinic of the Department of Haematology, Sultan Qaboos University Hospital for routine appointments and prescription medication or were admitted for pregnancy formed the control group in a ratio of $2: 1$ due to the consecutive enrolment during the study period. None of the patients included in the study were on a regular transfusion protocol for the prevention of SCA complications. All the patients in this study were confirmed to have SCA by high performance liquid chromatography. All patient data were collected from the hospital information system at the Sultan Qaboos University Hospital.

The Medical Research Ethics Committee of the Sultan Qaboos University Hospital approved the study (no. MREC 1491). Patient consent was not required due to the retrospective design of the study. The reporting of this study conforms to STROBE guidelines. ${ }^{21}$

\section{Data collection}

The data collected from the hospital information system included age, sex and SCAassociated complications, such as frequency of vaso-occlusive crisis (VOC), ACS, splenic sequestration and febrile episodes. The VOC frequency was categorized as high (>6 VOC/year), moderate (3-6 VOC/year) and low frequency (1-2 VOC/year). ACS was defined as patients presenting with fever and/or respiratory symptoms, accompanied by new infiltrates on the chest radiograph. Steady state was defined as the absence of fever or VOC in the previous $\geq 4$ weeks in the patient. Amongst the cases and controls, asplenia was defined as splenic atrophy as confirmed by ultrasound/computed tomography (CT) scan and/or past surgical splenectomy. All central venous catheter (CVC) lines used in these patients included peripherally inserted central lines, PORT-A-CATH ${ }^{\circledR}$, regular central line in the neck and femoral lines. The type of thrombosis, CVC insertion, hydroxyurea (HU) use and pregnancy details were recorded as clinical parameters. Laboratory data were recorded at baseline and during the thromboembolic episode in the cases. Haematological parameters included haemoglobin $(\mathrm{Hb})$ level, white blood cell (WBC) and platelet counts, reticulocyte $\%, \mathrm{HbS} \%$ and $\mathrm{HbF} \%$. Biochemical parameters included serum total bilirubin, serum lactic dehydrogenase 
(LDH), serum vitamin B12, serum fibrinogen, D-dimer and C-reactive protein (CRP). In addition, the radiological results of magnetic resonance imaging, CT angiography and abdominal ultrasound were recorded. The impact of VTE on morbidity and mortality in all patients was determined. VTEs were managed using a standard international protocol based on the American College of Chest Physicians guidelines. ${ }^{20}$

\section{Statistical analyses}

All statistical analyses were performed using IBM SPSS Statistics for Windows, Version 23.0 (IBM Corp., Armonk, NY, USA). Normally distributed continuous data are presented as mean \pm SD. Continuous data that were not normally distributed are presented as median with interquartile range (IQR). Mann-Whitney
$U$-test was used to compare the continuous data between the case and control groups; and between baseline and the VTE episode in the case group. Categorical data are presented as frequency of patients. Independent $t$-test was used to compare the continuous data between the case and control groups. $\chi^{2}$-test was used to compare the categorical data between the case and control groups. A $P$-value $<0.05$ was considered statistically significant.

\section{Results}

This retrospective case-control study enrolled 102 patients with SCA. Table 1 shows the demographic and clinical characteristics of the cases $(n=68)$ and controls $(n=34)$. The median age of the cases was 29.5 years (IQR 24.3, 35.0; range, 12-80 years) compared with 33.0 years (IQR

Table I. Demographic and clinical characteristics of patients with sickle cell anaemia with (case group, $n=68$ ) and without (control group, $n=34$ ) venous thromboembolism (VTE).

\begin{tabular}{llll}
\hline Characteristic & $\begin{array}{l}\text { Case group } \\
n=68\end{array}$ & $\begin{array}{l}\text { Control group } \\
n=34\end{array}$ & $\begin{array}{l}\text { Statistical } \\
\text { analyses }^{a}\end{array}$ \\
\hline Age, years & $29.5(24.3,35.0)$ & $33.0(24.0,41.3)$ & NS \\
Sex, male:female & $24: 44$ & $16: 18$ & NS \\
Age in males, years & $27.5(24.0,30.0)$ & $39.5(32.0,45.3)$ & NS \\
Age in females, years & $33.0(25.0,36.0)$ & $26.5(24.0,31.3)$ & NS \\
Haemoglobin genotype & & & \\
HbSS homozygotes & $64(94.1)$ & $30(88.2)$ & $\mathrm{NS}$ \\
Hb $\beta$-Thal/HbS & $4(5.9)$ & $2(5.9)$ & $\mathrm{NS}$ \\
History of ACS & $56(82.4)$ & $22(64.7)$ & $\mathrm{NS}$ \\
History of splenomegaly & $7(10.3)$ & $12(17.6)$ & $\mathrm{NS}$ \\
History of splenectomy & $50(73.5)$ & $17(50.3)$ & $\mathrm{NS}$ \\
VOC/year, I-2 & $25(36.8)$ & $12(35.3)$ & $\mathrm{NS}$ \\
VOC/year, 3-6 & $18(26.5)$ & $5(14.7)$ & $\mathrm{P}=0.04$ \\
VOC/year, $>6$ & $28(41.2)$ & $21(61.8)$ & $\mathrm{NS}$ \\
History of hydroxyurea therapy & $36(52.9)$ & $3(16.7)$ & $\mathrm{NS}$ \\
History of previous pregnancy & $12(27.3)$ & $0(0.0)$ & $P<0.05$ \\
History of pulmonary embolism & $16(36.4)$ & & \\
$\quad$ in pregnancy or puerperium & & & \\
\hline
\end{tabular}

Data presented as median (interquartile range) or $n$ of patients (\%).

a $\chi^{2}$-test was used to compare the categorical data between the case and control groups; NS, no significant between-group difference $(P \geq 0.05)$.

ACS, acute chest syndrome; VOC, vaso-occlusive crisis. 
$24.0,41.3$; range, $12-55$ years) for the control group. There were no significant differences in age and sex distribution between the two groups. Asplenia (including autosplenectomy) was observed in $50(73.5 \%)$ cases compared with $12(35.3 \%)$ controls, but the difference did not reach significance (Table 1). There was a significantly higher proportion of patients in the case group with high VOC frequency ( $>6 /$ year) compared with the control group $(P=0.04)$. There were no significant differences between the two groups in terms of $\mathrm{Hb}$ genotype, history of ACS, history of splenomegaly, history of HU therapy or the rate of pregnancy. A history of PE during pregnancy or puerperium (up to 6 weeks after delivery) was observed significantly more often in the case group than the control group $(P<0.05)$.

Amongst the haematological parameters (Table 2), there were significant differences between the two groups at baseline in $\mathrm{Hb}$, WBC count, reticulocytes, $\mathrm{HbS} \%$ and $\mathrm{HbF}$
$\% \quad(P<0.05$ for all comparisons $)$ CRP, $\mathrm{LDH}$ and total bilirubin were all significantly higher in the cases compared with the controls $(P<0.05$ for all comparisons). There were no significant differences between the two groups in terms of kidney function, liver function, tobacco use or ferritin levels (data not shown).

The pattern of thromboembolism in the study population is shown in Table 3 . Isolated PE and upper and lower limb DVT were the predominant presentations in the case group. Among the risk factors for thromboembolic complications, the rate of CVC insertion was significantly higher in the case group compared with the control group $(P<0.05)$. There were no significant differences in the rate of ACS or stroke between the two groups. The mortality rate was significantly higher in the case group compared with the control group $(P<0.05)$. Mortality in the case group was $10.3 \%(n=7)$, of which five died after

Table 2. Laboratory parameters in patients with sickle cell anaemia with (case group, $n=68$ ) and without (control group, $n=34$ ) venous thromboembolism (VTE).

\begin{tabular}{|c|c|c|c|c|c|}
\hline \multirow{3}{*}{$\frac{\text { Parameter }}{\text { Haemoglobin, g/dl }}$} & \multicolumn{3}{|c|}{ Case group $n=68$} & \multirow{3}{*}{$\begin{array}{l}\text { Control group } \\
n=34 \\
\text { At baseline } \\
9.9\end{array}$} & \multirow{3}{*}{$\begin{array}{l}\begin{array}{l}\text { Statistical } \\
\text { analyses }^{\mathrm{a}}\end{array} \\
\begin{array}{l}\text { Cases versus } \\
\text { controls }\end{array} \\
P<0.05\end{array}$} \\
\hline & \multirow{2}{*}{$\begin{array}{l}\text { At VTE } \\
\text { episode }\end{array}$} & \multicolumn{2}{|c|}{$\begin{array}{l}\text { At baseline versus } \\
\text { at VTE episode }\end{array}$} & & \\
\hline & & 9.7 & $P<0.05$ & & \\
\hline White blood cell count, $\times 10^{9} / \mathrm{l}$ & 12.7 & 10.1 & $P<0.05$ & 8.9 & $P<0.05$ \\
\hline Reticulocytes, \% & 5.3 & 5.4 & NS & 4.2 & $P<0.05$ \\
\hline Platelet count, $\times 10^{9} / \mathrm{l}$ & 392 & 400 & NS & 343 & NS \\
\hline Haemoglobin S,\% & 78.2 & & & 84.5 & $P<0.05$ \\
\hline Haemoglobin $\mathrm{F}, \%$ & 5 & & & 8.5 & $P<0.05$ \\
\hline Fibrinogen, g/l & 4 & & & 3.2 & NS \\
\hline Vitamin BI2, pmol/I & 222.5 & & & 253.5 & NS \\
\hline Serum lactic dehydrogenase, $u / l$ & 483 & 292 & $P<0.05$ & 334 & $P<0.05$ \\
\hline C-reactive protein, mg/l & 45 & & & 7 & $P<0.05$ \\
\hline Serum total bilirubin, $\mathrm{mg} / \mathrm{dl}$ & 39.5 & 25.0 & $P=0.03$ & 28.5 & $P<0.05$ \\
\hline Elevated D-Dimers & $37(54.4)$ & & & $0(0.0)$ & - \\
\hline
\end{tabular}

Data presented as median or $n$ of patients (\%).

aMann-Whitney $U$-test was used to compare the continuous data between the case and control groups; and between baseline and the VTE episode in the case group; NS, no significant between-group difference $(P \geq 0.05)$. 
Table 3. Comparison of events and outcomes in patients with sickle cell anaemia with (case group, $n=68$ ) and without (control group, $n=34$ ) venous thromboembolism (VTE).

\begin{tabular}{lccc}
\hline Outcomes & $\begin{array}{l}\text { Case group } \\
n=68\end{array}$ & $\begin{array}{l}\text { Control group } \\
n=34\end{array}$ & $\begin{array}{l}\text { Statistical } \\
\text { analyses }^{\mathrm{a}}\end{array}$ \\
\hline Isolated PE & $26(38.2)$ & $0(0.0)$ & $P<0.0005$ \\
DVT $^{\mathrm{b}}$ & $25(36.8)$ & & \\
Upper extremity DVT & $13(52.0)$ & $0(0.0)$ & $\mathrm{P}=0.002$ \\
Lower extremity DVT & $12(48.0)$ & $0(0.0)$ & $P=0.002$ \\
Other VTEs & $17(25.0)$ & $0(0.0)$ & $P=0.005$ \\
Ischaemic cerebral event & $10(58.8)$ & $0(0.0)$ & $\mathrm{P}=0.005$ \\
Right atrial and SVC thrombosis & $2(11.8)$ & $0(0.0)$ & $\mathrm{NS}$ \\
Abdominal vessel thrombosis & $5(29.4)$ & $0(0.0)$ & $P=0.04$ \\
Combined PE + VTE/DVTs & $6(8.8)$ & $0(0.0)$ & $P=0.03$ \\
CVC insertion & $29(42.6)$ & $3(8.8)$ & $\mathrm{P}<0.05$ \\
PE with CVC & $7(24.1)$ & $0(0.0)$ & $\mathrm{P}=0.02$ \\
UPper limb DVT with CVC & $18(62.1)$ & $0(0.0)$ & $\mathrm{NS}$ \\
Lower limb DVT with CVC & $4(13.8)$ & $0(0.0)$ & $\mathrm{NS}$ \\
ACS & $42(61.8)$ & $22(64.7)$ & $\mathrm{NS}$ \\
Stroke & $10(14.7)$ & $2(5.9)$ & $P<0.05$ \\
Death & $7(10.3)$ & $0(0.0)$ &
\end{tabular}

Data presented as $n$ of patients (\%).

${ }^{a} \chi^{2}$-test was used to compare the categorical data between the case and control groups; NS, no significant between-group difference $(P \geq 0.05)$.

bUpper extremity DVT: axillary, subclavian, internal jugular; Lower extremity DVT: all lower limb up to the iliac veins.

PE, pulmonary embolism; DVT, deep vein thrombosis; SVC, superior vena cava; CVC, central venous catheter; ACS, acute chest syndrome.

a PE episode and two died after having an ischaemic stroke.

There were moderate correlations between VTE and PE and CVC insertion, with correlation coefficients of $r=0.35$ and $\mathrm{r}=0.3$, respectively.

\section{Discussion}

Several studies have shown that VTE is one of the common complications of SCA with a cumulative incidence that increases with the age, with the mean age ranging from 24 to 37 years. ${ }^{18,19,22}$ Researchers have also compared SCA with inherited thrombophilia with a thrombosis prevalence around $25 \%$, which is similar to those seen in a family with strong thrombophilic defects. $^{23}$ In this current retrospective study, the median age of SCA patients that developed VTE was 29.5 years (range, 12-80 years), which was not significantly different from the median age of the control group (33.0 years) and similar to previous research. ${ }^{19}$ However, it was lower than the median age of 68 years for thrombosis seen in the general population. ${ }^{24}$ In addition, the current study found that sex was not a risk factor for VTE in patients with SCA, but the prevalence data indicated a preponderance for females, probably driven by pregnancy, although it did not reach statistical significance. These data were similar to another study from the US in which females were more at risk for VTE than males, again, not in keeping with the observations in the general population. ${ }^{19}$

The spectrum of thrombosis in the current study cohort revealed that DVT/VTEs $(n=42)$ were seen in more than half of the 
cases as compared with isolated PEs $(n=26)$. This has been reported in the previous studies. ${ }^{17,19}$ A previous study observed that the prevalence of DVT in SCA and non-SCA patients was similar, whereas, the prevalence of PE in SCA patients was twice that of non-SCA patients. $^{18}$ It has been suggested that thrombosis-in-situ could be responsible for this striking difference and that PE may be an aetiological factor in SCA patients that develop respiratory symptom. ${ }^{25}$ Pulmonary hypertension with tricuspid regurgitation jet velocity $\geq 2.5 \mathrm{~m} / \mathrm{s}$ is linked to VTE. ${ }^{26}$ Although, SCD is a hypercoagulable state, the contribution of VTE to an elevated tricuspid regurgitation velocity is unknown. ${ }^{26}$ This raises the possible pathogenic link between large-vessel venous thrombosis and the small-vessel thrombi observed in patients with sickle cell with pulmonary hypertension. $^{27}$ Although this current study found a high rate of PE and VTE, arterial thrombosis was rarely seen (one case each, for cerebral arterial and portal arterial thrombosis, but excluded from current data analysis).

One of the aims of this current study was to identify the predisposing factors that increase the risk of developing VTE in patients with SCA. There are a number of potential predisposing factors to thrombosis in SCA, including frequent hospitalizations, raised inflammation and hypercoagulable state associated with this disease, however, those factors are not well studied. Although the increased frequency of VOC is not a direct risk factor, it could be considered as a surrogate factor, since it leads to frequent and prolonged hospitalization of SCA patients, which is a risk factor for thromboembolism. This current study found that patients with more frequent VOCs had a significantly higher prevalence of VTE. This may again reflect disease severity and has been seen in other research. ${ }^{19}$ This current study found that a high percentage of the VTE patients had a history of ACS $(82.4 \%)$, implying that it did predispose to the occurrence of VTE, and such patients suffered from ACS as a complication of PE. Furthermore, previous research has demonstrated that $\mathrm{PE}$ is considered to significantly predispose for ACS, with PE episodes developing during $\mathrm{ACS},{ }^{25}$ which is again similar to these current observations. However, it is difficult to conclude (from the current data), whether PE is a cause or a consequence of $\mathrm{ACS}^{28}$ It is believed that patients with SCA are more prone to infection as a result of immune impairment because of asplenia. ${ }^{29}$ Infection, by promoting an increase in inflammatory cytokines, can provoke thrombosis, especially in asplenic patients. ${ }^{30}$ Furthermore, asplenia in haemolytic diseases including SCA was reported to be associated with an increased risk of thrombosis, as seen in this current study. ${ }^{16}$

Central venous catheter insertion has a significant correlation with VTE episodes. ${ }^{15}$ $\mathrm{CVC}$ is generally required for many patients with SCA and it has been shown to be an independent risk factor for VTE. ${ }^{15,31}$ Furthermore, prolonged use of catheter implantation increases the risk of thrombosis, ${ }^{17,31}$ as seen in the current study cohort. Among the 68 patients with VTE in the case group, 29 patients had CVC at the time of VTE, including 18 with upper limb DVT, seven with PE and four had lower limb DVT.

Pregnancy is significantly correlated with VTE as the rate of VTE during pregnancy and puerperium was 1.5-2.5-times greater than in non-pregnant SCA women. ${ }^{32,33}$ It is reported that pregnancy-related VTE in females with SCA is 1.5-5-times greater than pregnancy-related VTE in the general population. $^{32}$ The current study demonstrated that $27.3 \%$ of cases compared with $16.7 \%$ of controls had a history of pregnancy. Interestingly, PE was reported in 16 $(36.4 \%)$ of females in the case group, 
whereas none of the three pregnant females in the control group developed PE $(P<0.05)$. There are several possible explanations for this, such as impaired venous return from lower limbs, high level of steroid hormones and changes in the haemostatic system, in addition to SCA, which together contribute to elevate the risk of thrombosis during the pregnancy period. ${ }^{32,33}$ This has led to the recommendation of prophylactic anticoagulation in all pregnant patients with SCA. ${ }^{34}$

The use of HU therapy over the last 30 years has been shown to increase $\mathrm{HbF}$ in SCA patients leading to improved clinical efficacy. ${ }^{35}$ It is associated with a reduction in the levels of biomarkers of hypercoagulability in SCA patients and is likely to reduce the prevalence of VTE. ${ }^{36}$ In this current study, the median $\mathrm{HbF}$ levels were significantly higher in the control group compared with the case group. Furthermore, a higher percentage of control patients $(61.8 \%)$ were treated with HU compared with $52.9 \%$ in the case group, which might explain the higher median $\mathrm{HbF}$ in the controls. Although there are contradicting results on the impact of HU on VTE prevention, these current results were in inconclusive with respect to a positive role of $\mathrm{HU}$ in VTE prevention, knowing that that $\mathrm{HbF}$ inhibits intracellular $\mathrm{HbS}$ polymerization. ${ }^{37,38}$

In the current study population, there were elevations in the median WBC count, LDH level, bilirubin and CRP in the case group from baseline to VTE episode; and the baseline levels were significantly different compared with the control group. Higher WBC count and elevated LDH level are reported to be risk factors for VTE in SCA. ${ }^{39}$ Biomarkers are helpful in identifying different pathophysiological mechanisms in SCA, including hypercoagulability, haemolysis, nitric oxide depletion, inflammation, oxidative stress, vasculopathy, reperfusion injury and tissue necrosis with infarction. ${ }^{7-10,19,25}$ Over half of the patients in the case group in the current study had elevated D-dimer $(54.4 \%)$ at the VTE episode and the CRP levels were significantly higher at the VTE episode compared with the controls at baseline, which were presumably due to an acute phase reaction, often seen in patients with thromboembolism and in sickle cell crisis. ${ }^{33}$

Among the clinical complications of VTE in this current group of patients, a large majority of the patients in the case group developed ACS (61.8\%), which was consequential of the development of PE; and 10 patients $(14.7 \%)$ developed stroke as a manifestation of venous and arterial thrombosis within cerebral vessels. In 306 autopsies of SCA patients, a previous study reported that $9.8 \%$ died due to stroke and $4.9 \%$ died due to pulmonary emboli/thrombi. ${ }^{40}$ However, another autopsy study from Nigeria reported that the mortality rate from fatal thromboembolic complications was $37 \%{ }^{41}$ Thus, although infections and multiorgan failure are major causes of death in SCA, SCA with VTE is still associated with a significant mortality. ${ }^{40,41}$ These data support the regular use of prophylactic low molecular weight heparin for the purpose of VTE prevention and improved VOC management. ${ }^{42,43}$

In conclusion, acknowledging the limitation of the retrospective nature of this current study, VTE was one of the common complications of SCA and it occurred at a younger age than the general population. PE showed a higher prevalence in patients with SCA. Several risk factors contributed to the development of VTE in patients with SCA such as CVC insertion and pregnancy. In addition, coagulation activity in patients with SCA was enhanced with abnormal activation of the fibrinolytic system and increased levels of WBCs, $\mathrm{LDH}$, bilirubin and CRP. This current study demonstrated that thromboembolic complications in patients with SCA had a high impact on 
morbidity and mortality and calls for the use of prophylactic anticoagulation in all patients with SCA during their hospital stay.

\section{Acknowledgements}

We wish to thank the hospital administration for the use of hospital materials in this study.

\section{Author contributions}

All authors made substantial contributions. They have all seen and approved the final version of the manuscript. S.A., A.R.A., S.R.A, S. Y.A., N.F., S.K.B. and A.V.P. were fully involved in the conception and design of the study, recruitment and care of patients, acquisition of data, or analysis and interpretation of the data. S.A. and A.V.P. were instrumental in the drafting the article and critical appraisal before submission.

\section{Declaration of conflicting interest}

The authors declare that there are no conflicts of interest.

\section{Funding}

This research received no specific grant from funding agency in the public, commercial, or not-for-profit sectors.

\section{ORCID iD}

Salam Alkindi (D) https://orcid.org/0000-00016863-5748

\section{References}

1. Quirolo K and Vichinsky E. Sickle cell anemia, thalassemia, and congenital hemolytic anemias. In: Toby L. Simon, Jeffrey McCullough, Edward L. Snyder, Bjarte G. Solheim and Ronald G. Strauss (eds) Rossi's Principles of Transfusion Medicine. 5th ed. Chapter 11, John Wiley \& Sons, Ltd. Published 2016 by John Wiley \& Sons, Ltd., 2016, p.126.

2. GBD 2013 Mortality and Causes of Death Collaborators. Global, regional, and national age-sex specific all-cause and causespecific mortality for 240 causes of death, 1990-2013: a systematic analysis for the
Global Burden of Disease Study 2013. Lancet 2015; 385: 117-171. doi: 10.1016/ S0140-6736(14)61682-2.

3. Al-Riyami AA, Suleiman AJ, Afifi M, et al. A community-based study of common hereditary blood disorders in Oman. East Mediterr Health J 2001; 7: 1004-1011.

4. Alkindi S, Al Zadjali S, Al Madhani A, et al. Forecasting hemoglobinopathy burden through neonatal screening in Omani neonates. Hemoglobin 2010; 34: 135-144. doi: 10.3109/03630261003677213.

5. Bender MA. Sickle Cell Disease. In: Adam MP, Ardinger HH, Pagon RA, Wallace SE, Bean LJH, Stephens K and Amemiya A (eds) Gene Reviews ${ }^{\circledR}$. Seattle (WA): University of Washington, Seattle; 19932021. 2003 Sep 15 [updated 28 Jan 2021].

6. Bunn HF. Pathogenesis and treatment of sickle cell disease. $N$ Engl J Med 1997; 337: 762-769. DOI: 10.1056/NEJM199709113 371107

7. Odièvre MH, Verger E, Silva-Pinto AS, et al. Pathophysiological insights in sickle cell disease. Indian J Med Res 2011; 134: 532-537.

8. Kato GJ, Steinberg MH and Gladwin MT. Intravascular hemolysis and the pathophysiology of sickle cell disease. J Clin Invest 2017; 127: 750-760. doi: 10.1172/JCI89741.

9. Manwani D and Frenette PS. Vaso-occlusion in sickle cell disease: pathophysiology and novel targeted therapies Blood 2013; 122: 3892-3898. doi: 10.1182/blood-201305-498311

10. Kaul DK, Finnegan E and Barabino GA. Sickle red cell-endothelium interactions. Microcirculation 2009; 16: 97-111. doi: 10.1080/10739680802279394

11. Miller AC and Gladwin MT. Pulmonary Complications of Sickle Cell Disease. Am J Respir Crit Care Med 2012; 185: 1154-1165. doi: 10.1164/rccm.201111-2082CI

12. Siddiqui $\mathrm{AK}$ and Ahmed S. Pulmonary manifestations of sickle cell disease. Postgrad Med J 2003; 79: 384-390.

13. Ogun GO, Ebili H and Kotila TR. Autopsy findings and pattern of mortality in Nigerian sickle cell disease patients. Pan Afr Med J 2014; 18: 30. doi: 10.11604/pamj.2014.18. 30.4043 
14. Minter KR and Gladwin MT. Pulmonary complications of sickle cell anemia. A need for increased recognition, treatment, and research. Am J Respir Crit Care Med 2001; 164: 2016-2019. DOI: 10.1164/ajrccm.164. 11.2104101

15. Kumar R, Stanek J, Creary S, et al. Prevalence and risk factors for venous thromboembolism in children with sickle cell disease: an administrative database study. Blood Adv 2018; 2: 285-291. doi: 10.1182/bloodadvances.2017012336.

16. Naik RP, Streiff MB and Lanzkron S. Sickle cell disease and venous thromboembolism: what the anticoagulation expert needs to know. J Thromb Thrombolysis 2013; 35: 352-358. doi: 10.1007/s11239-013-0895-y

17. van Hamel Parsons V, Gardner K, Patel R, et al. Venous thromboembolism in adults with sickle cell disease: experience of a single centre in the UK. Ann Hematol 2016; 95: 227-232. DOI: 10.1007/s00277015-2531-8

18. Stein PD, Beemath A, Meyers FA, et al. Deep venous thrombosis and pulmonary embolism in hospitalized patients with sickle cell disease. Am J Med 2006; 119: 897.e7-11. DOI: 10.1016/j.amjmed.2006.08.015

19. Brunson A, Lei A, Rosenberg A, et al. Increased incidence of VTE in sickle cell disease patients: risk factors, recurrence and impact on mortality. Br J Haematol 2017; 178: 319-326. doi: 10.1111/bjh.14655

20. Naik RP, Streiff, MB, Haywood, C, et al. Venous thromboembolism incidence in the Cooperative Study of Sickle Cell Disease. J Thromb Haemost 2014; 12: 2010-2016. doi: $10.1111 /$ jth. 12744

21. von Elm E, Altman DG, Egger M, et al. The Strengthening the Reporting of Observational Studies in Epidemiology (STROBE) statement: guidelines for reporting observational studies. Ann Intern Med 2007; 147: 573-577.

22. Woods GM, Sharma R, Creary S, et al. Venous Thromboembolism in Children with Sickle Cell Disease: A Retrospective Cohort Study. J Pediatr 2018; 197: 186-190.e1. doi: 10.1016/j.jpeds.2018.01.073

23. Lijfering WM, Brouwer JL, Veeger NJ, et al. Selective testing for thrombophilia in patients with first venous thrombosis: results from a retrospective family cohort study on absolute thrombotic risk for currently known thrombophilic defects in 2479 relatives. Blood 2009; 113: 5314-5322.

24. Spencer FA, Emery C, Joffe SW, et al. Incidence rates, clinical profile, and outcomes of patients with venous thromboembolism: the Worcester VTE study. J Thromb Thrombolysis 2009; 28: 401-409.

25. Lazarus SG, Kelleman M, Adisa O, et al. Are we missing the mark? Fever, respiratory symptoms, chest radiographs, and acute chest syndrome in sickle cell disease $\mathrm{Am} J$ Hematol 2016; 91: E332-E333. doi: 10.1002/ajh.24408.

26. Adams RM, Kopel LS, Bland DA, et al. An Elevated TRV Is Associated with Venous Thromboembolism in Sickle Cell Disease. Blood 2012; 120(21): 3222. https: //doi.org/ 10.1182/blood.V120.21.3222.3222.

27. Haque AK, Gokhale S, Rampy BA, et al. Pulmonary hypertension in sickle cell hemoglobinopathy: A clinicopathologic study of 20 cases. Hum Pathol 2002; 33: 1037-1043.

28. Mehari A, Igbineweka N, Allen D, et al. Abnormal Ventilation-Perfusion Scan Is Associated with Pulmonary Hypertension in Sickle Cell Adults. J Nucl Med 2019; 60: 86-92. doi: 10 .2967/jnumed. 118.211466. Epub 2018 Jun 7.

29. Cappellini MD. Coagulation in the pathophysiology of hemolytic anemias. Hematology Am Soc Hematol Educ Program 2007: 74-78. doi: 10.1182/asheducation2007.1.74.

30. Beristain-Covarrubias N, Perez-Toledo M, Thomas MR, et al. Understanding Infection-Induced Thrombosis: Lessons Learned From Animal Models. Front Immunol 2019; 10: 2569. doi: 10.3389/ fimmu. 2019.02569

31. Alkindi S, Matwani S, Al-Maawali A, et al. Complications of PORT-A-CATH ${ }^{\circledR}$ in patients with sickle cell disease. $J$ Infect Public Health 2012; 5: 57-62. doi: 10.1016/ j.jiph.2011.10.004

32. Seaman CD, Yabes J, Li J, et al. Venous thromboembolism in pregnant women with sickle cell disease: a retrospective database 
analysis. Thromb Res 2014; 134: 1249-1252. doi: 10.1016/j.thromres.2014.09.037

33. Noubouossie D and Key NS. Sickle cell disease and venous thromboembolism in pregnancy and the puerperium. Thromb Res 2015; 135: S46-S48. doi: 10.1016/S00493848(15)50442-8

34. Guyatt GH, Norris SL, Schulman S, et al. Methodology for the development of antithrombotic therapy and prevention of thrombosis guidelines: Antithrombotic Therapy and Prevention of Thrombosis, 9th ed: American College of Chest Physicians Evidence-Based Clinical Practice Guidelines. Chest 2012; 141: 53S-70S. doi: 10.1378/chest.11-2288

35. Ware RE, de Montalembert M, Tshilolo L, et al. Sickle cell disease. Lancet 2017; 390: 311-323. doi: 10.1016/S0140-6736 (17) 30193-9

36. Colella MP, De Paula EV, Conran N, et al. Hydroxyurea is associated with reductions in hypercoagulability markers in sickle cell anemia. $J$ Thromb Haemost 2012; 10: 1967-1970. doi: 10.1111/j.1538-7836.2012. 04861. $x$

37. Wild BJ and Bain BJ. Investigation of abnormal haemoglobins and thalassaemia. In: Lewis SM, Bain BJ and Bates I (eds) Dacie and Lewis Practical Haematology. 9th ed. Chapter 12. London: Churchill Livingstone, 2001, reprinted 2002, pp.233.

38. Srisuwananukorn A, Raslan R, Zhang X, et al. Clinical, laboratory, and genetic risk factors for thrombosis in sickle cell disease. Blood Adv 2020; 4: 1978-1986. doi: 10.1182/ bloodadvances 2019001384

39. Damanhouri GA, Jarullah J, Marouf S, et al. Clinical biomarkers in sickle cell disease. Saudi J Biol Sci 2015; 22: 24-31. doi: 10.1016/j.sjbs.2014.09.005

40. Manci EA, Culberson DE, Yang YM, et al. Causes of death in sickle cell disease: an autopsy study. $\mathrm{Br} J$ Haematol 2003; 123: 359-365.

41. Quinn CT and Miller ST. Risk factors and prediction of outcomes in children and adolescents who have sickle cell anemia. Hematol Oncol Clin North Am 2004; 18: 1339-1354.

42. Qari MH, Aljaouni SK, Alardawi MS, et al. Reduction of painful vaso-occlusive crisis of sickle cell anaemia by tinzaparin in a doubleblind randomized trial. Thromb Haemost 2007; 98: 392-396.

43. Mousa SA, Al Momen A, Al Sayegh F, et al. Management of painful vaso-occlusive crisis of sickle-cell anemia: consensus opinion. Clin Appl Thromb Hemost 2010; 16: 365-376. doi: 10.1177/1076029609352661 